\title{
EVALUATION OF ASTER GDEM v.2 USING GPS CHECKPOINTS, OSGB DEM VALUES AND PHOTOGAMMETRICALLY DERIVED DEMS
}

\author{
Haval Sadeq, Jane Drummond, Zhenhong Li. \\ School of Geographical and Earth Sciences, College of Science and Engineering, University of Glasgow, G12 8QQ, UK. \\ (jane.drummond@glasgow.ac.uk).
}

Commission IV, WG IV/6

KEYWORDS: ASTER GDEM, accuracy, bias, test-sites, slope-effect, coastal-effect.

\begin{abstract}
:
A 2010 study examining ASTER GDEM v1 data revealed accuracies of 12-25m and strong negative discrepancy biases compared to precise GPS observations, in several test sites in China. Rather than further investigating these, with the advent of ASTER GDEM v2 a new series of tests, also using precise GPS observations but also other DEMs, was performed. In these tests better than the expected $17 \mathrm{~m}$ accuracies were found (RMSE values of $3.9 \mathrm{~m}$ to $15.3 \mathrm{~m}$ ) and no strong biases.
\end{abstract}

\section{BACKGROUND}

A study, with colleagues ( $\mathrm{Li}$, et al., 2012) revealed accuracies of $12-25 \mathrm{~m}$ in five Chinese test areas when comparing ASTER GDEM v1 values with high accuracy GPS check points. This accuracy was poorer than expected, but also exposed a strong negative bias in most of the test areas. For purposes of comparison SRTM data of the test areas were also investigated revealing no negative bias. The test areas were coastal, agricultural, steep /mountainous and high plateau. We proposed several reasons for the bias including landcover effects, the lack of a water mask and other systematic errors in the data processing. It was planned to look at the data further in more extensive areas in China and three test sites in the UK (mountainous, coastal and agricultural). However the very recent advent (October, 2011) of ASTER GDEM v2 encouraged us to immediately investigate these new data, particularly with respect to the negative bias, using the three British test areas, only. Comparisons were planned with GPS check points, $10 \mathrm{~m}$ DTMs supplied by the national mapping organization (Ordnance Survey of Great Britain or OSGB) and in-house generated digital photogrammetric DTMs. Investigation has shown improved accuracy $(15.2 \mathrm{~m}, 8.7 \mathrm{~m}$ and $3.7 \mathrm{~m}$, respectively) in the three sites. This paper will present the findings and details of our validation with regard to the three test areas and the four data sources (ASTER GDEM v2; OSGB Profile DTMs; digital photogrammetry; high accuracy GPS).

\section{TEST AREAS}

The test areas are Plockton (forest /mountainous), Caerlaverock Merse (coastal/ salt-marsh/pasture), Wicken Fen (low lying/ inland/arable). They are located in northern, central, and southern Britain, as follows (shown by their approx. centrepoints' Lat/Long):

$\begin{array}{lll} & \text { Lat } & \text { Long } \\ \text { Plockton } & 57.33^{\circ} \mathrm{N} & 5.61^{\circ} \mathrm{W} \\ \text { Caerlaverock Merse } & 54.98^{\circ} \mathrm{N} & 3.54^{\circ} \mathrm{W} \\ \text { Wicken Fen } & 52.33^{\circ} \mathrm{N} & 0.31^{\circ} \mathrm{E}\end{array}$

The three areas are well known to the authors. Precise GPS observations had been gathered in Plockton in 2007, and these are utilised. The GPS derived coordinates of these points are shown in Table 1, with their ASTER, OSGB and photogrammetric heights (derived from digitally processed 1:14000 scale RC20 aerial photography, flown 2004); all heights are on the ODN vertical datum (that used by OSGB).

\section{METHODOLOGY}

For all three areas ASTER GDEM v2 was compared with OSGB Profile DTMs. The ASTER GDEM v2 is supplied at 1 arc-second resolution (approx. 30x15m at the UK's latitude), with geographical coordinates based on the WGS84 ellipsoid and height values based on the EGM96 geoid. The coordinates used by ASTER are the same as the Google Earth reference system, importantly with heights, for the UK, some 30m different from those based on the WGS84 ellipsoid, according to Lemoine et al. (1998). The difference between the EGM96 and ODN is small, being about $80 \mathrm{~cm}$ over the British Isles (Stillman, 2009). The data sets were imported into ArcMap having been appropriately labelled for their original planimetric coordinates (ASTER: Lat, Long on WGS84; OSGB Profile: BNG). The project in ArcMap was set up with BNG planimetric coordinates, thus, on import to ArcMap, ASTER Lat, Long values were displayed as BNG coordinates. The height correction, ensuring both terrain models were based on the same vertical datum (ODN), involved a simple $-80 \mathrm{~cm}$ shift to the ASTER data. Thus all terrain models were approximately the same resolution, and the same coordinate frame and vertical datum.

ASTER GDEM v2 and OSGB Profile terrain models were processed to provide 'difference maps' (Figs 1a, 3a, 4a). The average difference in each case is: $0.8 \mathrm{~m}, 0.4 \mathrm{~m}$ and $4.9 \mathrm{~m}$, and considerably less than in our previous study using ASTER GDEM v1 data (typically $20-30 \mathrm{~m}$ ). Histograms of the distribution of values from each of the 'difference maps' do not show the negative bias previously identified (Figs 2c, 3c, 4c). The greatest differences tend to be found in steep, forested areas and the smallest differences in the areas of pastureland, with arable land intermediate; but, anomalously, in the third test site (Wicken Fen) very high differences were found in low-lying (below sea-level, but inland) arable land.

Table 1 shows the E, $\mathrm{N}$ and elevation values of the fifteen precise GPS points, the height value of those same points from the ASTER GDEM v2, the OSGB Profile and the (incomplete) photogrammetric terrain models, giving RMSE's of 7.3, 2.1 and 3.7m, respectively. 
TABLE 1. Check point accuracies derived from precise GPS points 1001:1015 and their corresponding ASTER GDEMv2, OSGB and photogrammetrically derived heights (all heights with respect to the ODN vertical datum).

\begin{tabular}{|l|l|l|l|l|l|l|}
\hline Pnt \# & Eastings & Northings & $\begin{array}{l}\text { GPS } \\
\text { height }\end{array}$ & $\begin{array}{l}\text { ASTER } \\
\text { height }\end{array}$ & $\begin{array}{l}\text { OSGB } \\
\text { height }\end{array}$ & $\begin{array}{l}\text { Photogramm. } \\
\text { height }\end{array}$ \\
\hline 1001 & 178689.5 & 832767.9 & 28 & 15 & 29 & 28 \\
\hline 1002 & 178880.0 & 832864.3 & 22 & 10 & 23 & 22 \\
\hline 1003 & 179457.5 & 832991.9 & 29 & 22 & 28 & 22 \\
\hline 1004 & 178122.3 & 831466.6 & 26 & 18 & 24 & 26 \\
\hline 1005 & 178448.0 & 831315.6 & 32 & 28 & 34 & 32 \\
\hline 1006 & 177919.5 & 830051.4 & 96 & 91 & 99 & 96 \\
\hline 1007 & 178461.6 & 830410.8 & 151 & 153 & 151 & 151 \\
\hline 1008 & 180259.2 & 831473.0 & 95 & 102 & 99 & 114 \\
\hline 1009 & 179626.8 & 830507.6 & 122 & 114 & 122 & Na \\
\hline 1010 & 180518.2 & 832624.5 & 84 & 88 & 86 & Na \\
\hline 1011 & 180440.1 & 830944.9 & 105 & 109 & 108 & Na \\
\hline 1012 & 181591.5 & 833072.5 & 45 & 55 & 49 & 52 \\
\hline 1013 & 182388.6 & 833039.8 & 52 & 54 & 52 & 52 \\
\hline 1014 & 181457.2 & 831303.2 & 140 & 142 & 140 & 140 \\
\hline 1015 & 182234.0 & 831316.3 & 144 & 153 & 145 & 143 \\
\hline $\begin{array}{l}\text { RMS w.r.t. } \\
\text { GPS height }\end{array}$ & & & & $7.3 \mathrm{~m}$ & $2.1 \mathrm{~m}$ & $3.7 \mathrm{~m}$ \\
\hline
\end{tabular}

\section{RESULTS}

The findings for Plockton are shown in Figures 1 and 2, for Caerlaverock Merse in Figure 3 and for Wicken Fen in Figure 4. The same methods are used in all three areas, that is producing a difference map of the Aster and OSGB terrain models - heights with respect to the same vertical datum (ODN). Shifts from EGM96 to ODN are from the GoogleEarth-Plotter facility (Stillman, 2009). The legend for differences between OSGB and ASTER is similar for each test area and is in Fig 1a for the Plockton case.

Some consideration was given to the stack numbers also supplied with ASTER GDEM v2. This gives, per pixel, the number of images processed to provide heights. In the Plockton case the maximum number was 7 , which is low, and the mean was 4 ; results are quoted as being especially poor for stack numbers of 4 or less (MicroImages, 2009). The correlation coefficient for stack number against absolute height differences was only -0.07 , indicating stack numbers' unimportance in this case.

\section{CONCLUSIONS}

The ASTER GDEM v2 data are within their specified accuracy of $17 \mathrm{~m}$ and show no large negative bias; the Wicken Fen area shows a small positive bias. Perhaps the bias previously found related to the choice of datum? Largest discrepancies are found where slopes are steep and in coastal, low lying areas where image matching may be difficult. An anomalous situation (level arable land below sea-level) requires further consideration, particularly considering
ASTER GDEM's potential use for flood management in these and coastal areas.

\section{REFERENCES}

Lemoine, FG., Kenyon, SC., Factor, JK., Trimmer, RG., Pavlis, NK., Chinn,DS., Cox, CM., Klosko, SM., Luthcke, SB., Torrence, MH., Wang, YM., Williamson, RG., Pavlis, EC., Rapp, RH. and Olson, Tr., 1998. "The Developoment of the Joint NASA GSFC and NIMA Geopotential Model EGM96”,

http://cddis.nasa.gov/926/egm96/ egm96.html

Li, P., Li, Z., Shi, C., Muller, J-P., Drummond, J., and Liu, J., 2012. "Validation of ASTER GDEM Using GPS Benchmarks and SRTM over China”, Int.Jo.RS, in press.

Stillman, D.M., 2009. "Plotting Surveying Data in Google Earth”, http//code.google.com/ p/google-earth-plotter

MicroImages Inc, 2009. "ASTER GDEM Accuracy Assessment” http://www.microimages.com/documentation/ TechGuides/75asterDEM.pdf

\section{ACKNOWLEDGEMENTS}

Anne Dunlop, Kenny Roberts and the BSc Class of 2007 GeoInfo\&MappingScience students, Glasgow Univ., for GPS observations.

(\$) Crown Copyright/DatabaseRight 2012. An Ordnance Survey/EDINA supplied service. 
Figure 1. Plockton Study area.

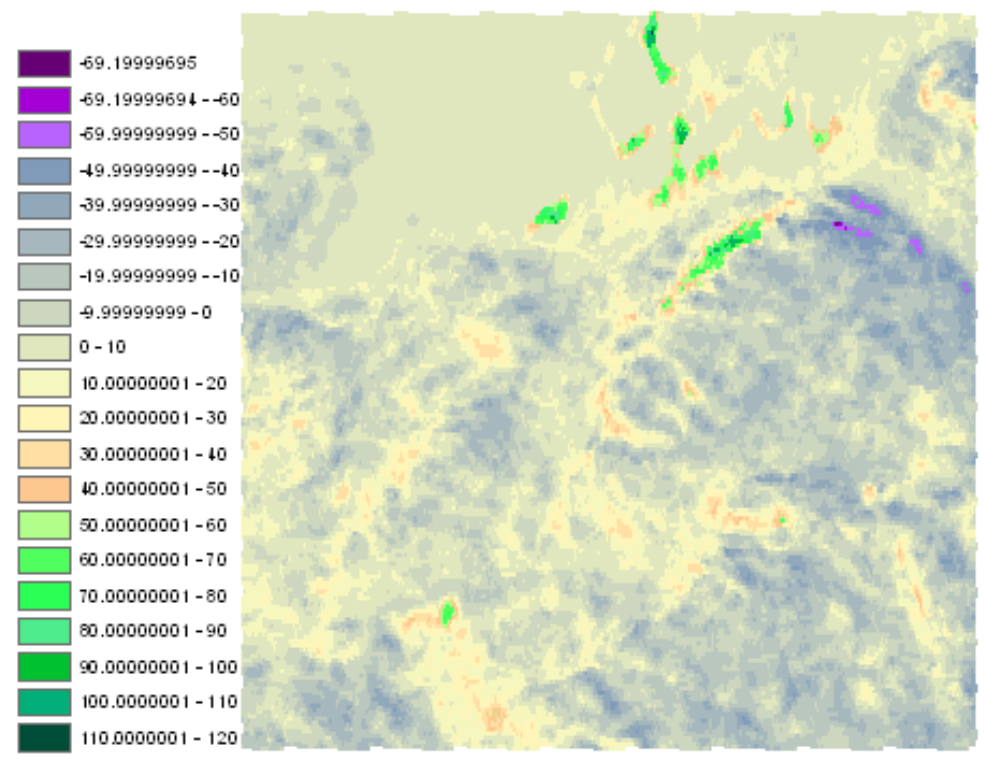

Figure 1a. ASTER GDEM v2 and OSGB Height Differences, for Plockton, created from Figs. 2a and 2b (below). Green pixels are those whose positive difference exceeds three times the RMS Difference and purple pixels are those whose negative difference exceeds three times the RMS Difference, coinciding with steep forested areas and intertidal islands, in this case, as can be seen in Figure 1b.

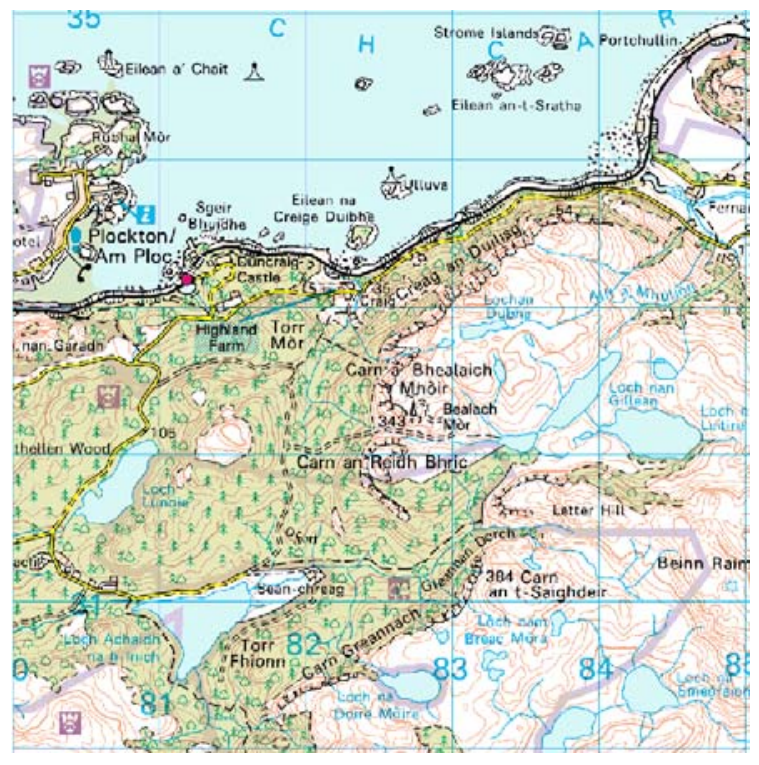

Figure 1b.Topographic map of Plockton - an area of coastal (some intertidal) islands, inland lakes, steep rocky slopes, forested and un-forested mountains. 
International Archives of the Photogrammetry, Remote Sensing and Spatial Information Sciences, Volume XXXIX-B4, 2012 XXII ISPRS Congress, 25 August - 01 September 2012, Melbourne, Australia

Figure 2. Plockton Study area, continued.

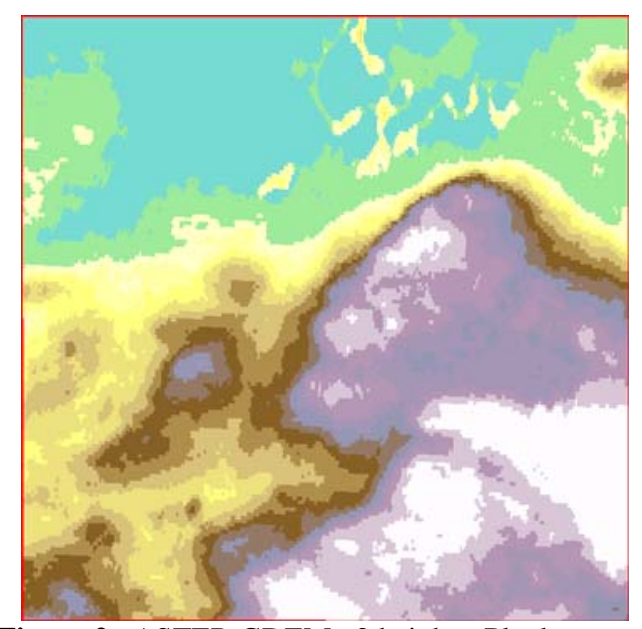

Figure 2a ASTER GDEM v2 heights, Plockton area

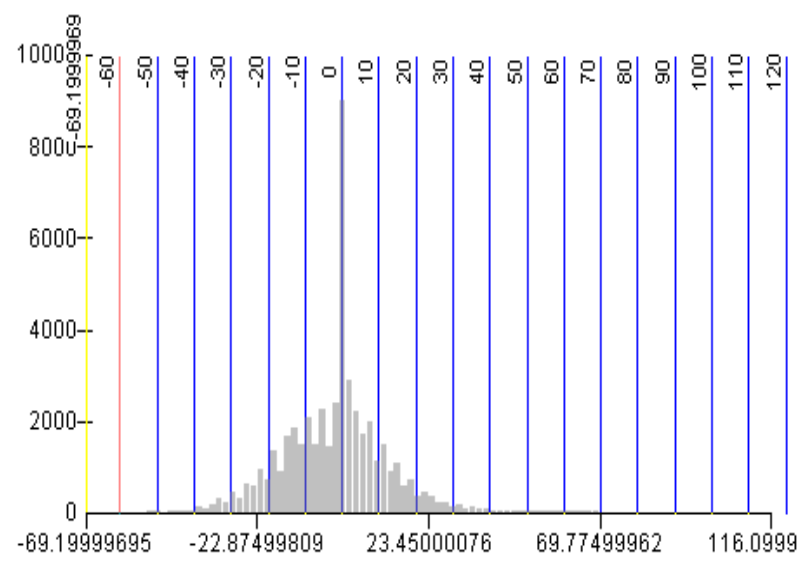

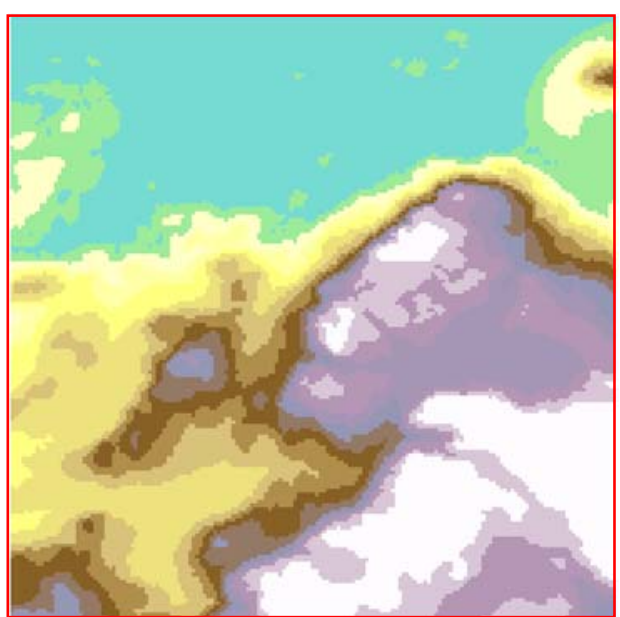

Figure 2b OSGB Profile heights, Plockton area.

Figure 2c. Histogram of differences, Plockton, between ASTER v2 and OSGB terrain models

Largest negative difference/error: $66.2 \mathrm{~m}$ Largest positive difference/error: $116.1 \mathrm{~m}$

Mean difference:

$-1.1 \mathrm{~m}$

RMS diff:

15.3 
Figure 3. Caerlaverock Study Area

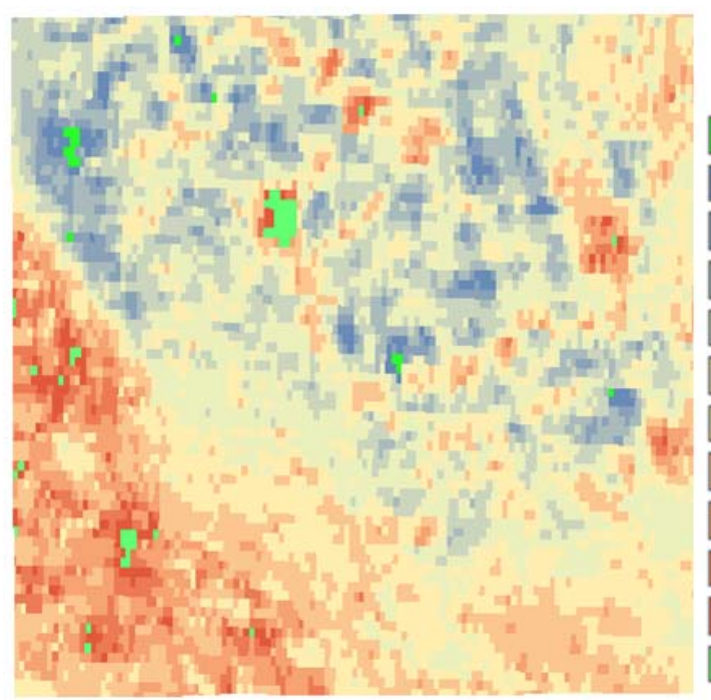

Differences

-30 to -25

-25 to -20

-20 to -15

-15 to -10

-10 to -5

-5 to 0

0 to 5

5 to 10

10 to 15

15 to 20

20 to 25

25 to 30

Fig 3a. . Difference between ASTER v2 and OSGB heights in Caerlaverock area. (Green pixels are tnose witn posıtıve or negative differences $>3 \times$ RMSdifferences)

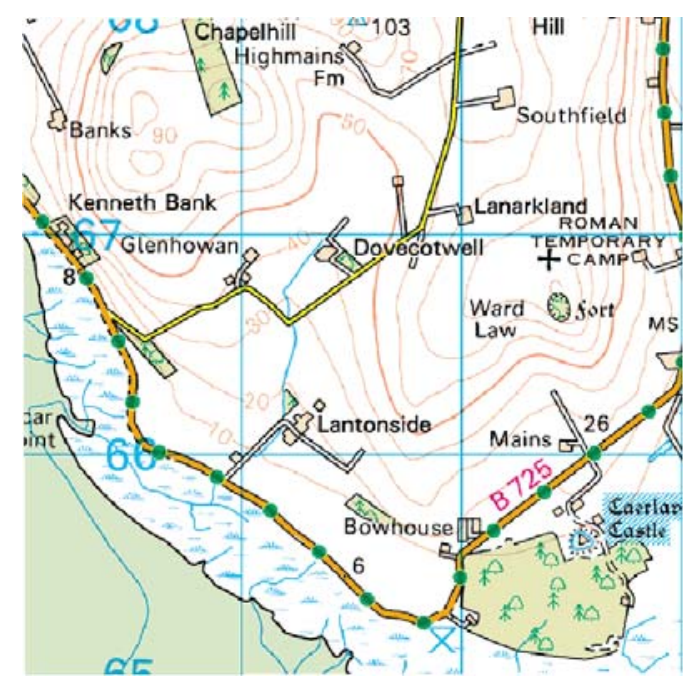

Fig 3b. Topographic map of Caerlaverock - an area of salt-marsh and pasture, without steep slopes.

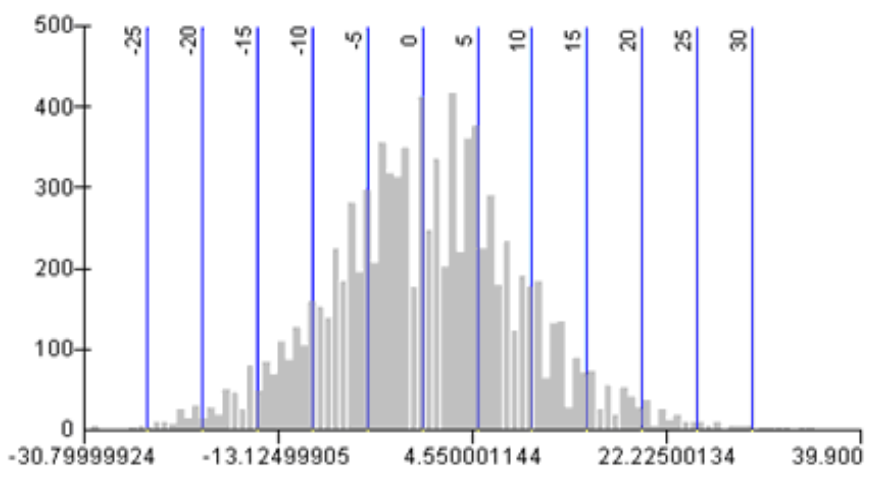

Fig 3c. Histogram of Differences, Caerlaverock, between ASTER v2 and OSGB terrain models

Largest negative diff./error:

$-30.7 \mathrm{~m}$

Largest positive diff./error:

$39.9 \mathrm{~m}$

Mean difference:

$0.4 \mathrm{~m}$

RMS diff.

$8.8 \mathrm{~m}$ 
Figure 4. Wicken Fen Study Area

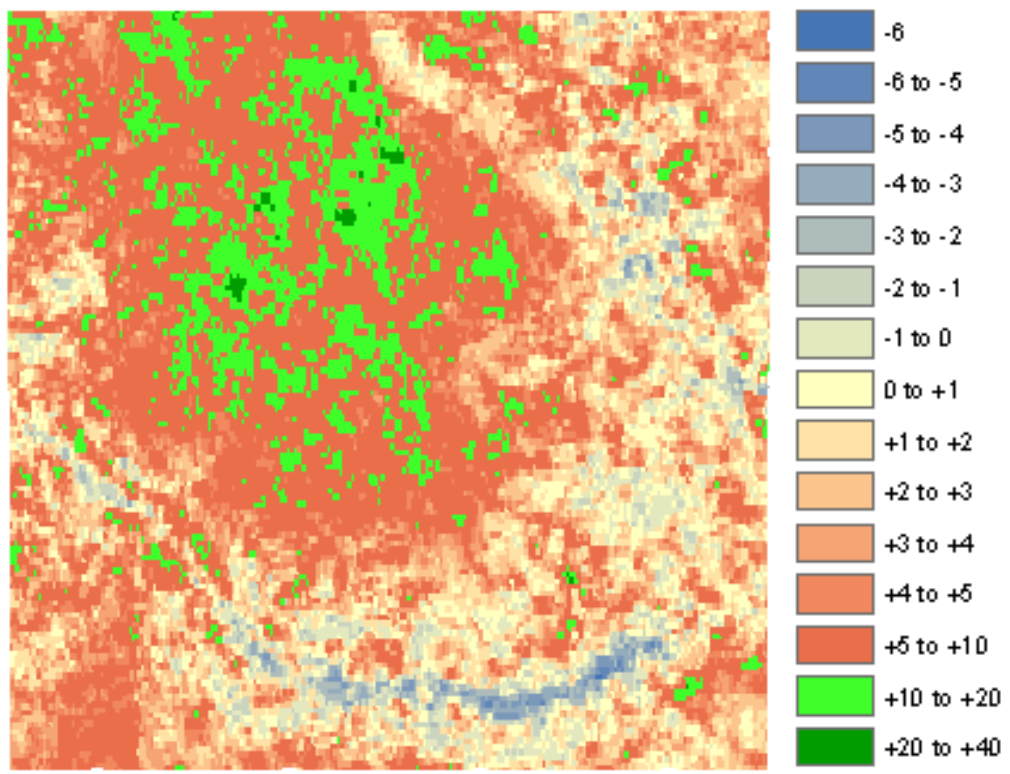

Figure 4a. Difference between ASTER v2 and OSGB heights in Wicken area. (Green pixels are those with discrepancies $>3 \mathrm{x}$ RMSdifferences)

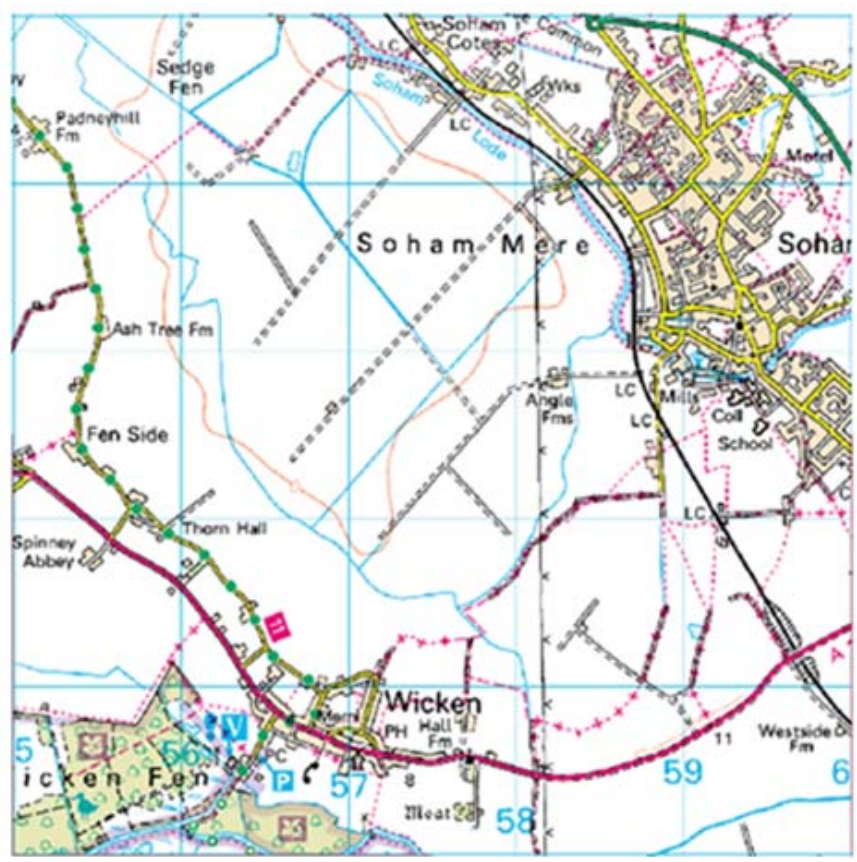

Figure 4b. Topographic Map of Wicken area (extremely level, low-lying - some, Soham Mere - below sea-level), arable and residential terrain)

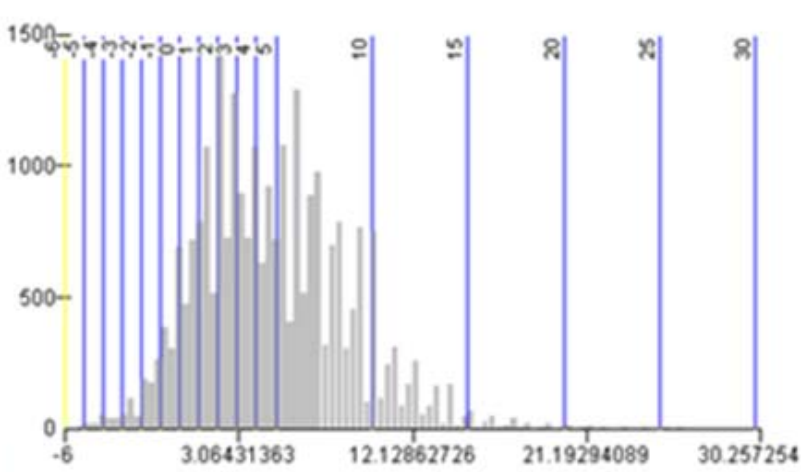

Figure 4c. Histogram of differences between ASTER v2 and OSGB terrain models, Wicken Fen area.

Largest negative diff./error: $-6.0 \mathrm{~m}$

Largest positive diff./error: $30.3 \mathrm{~m}$

Mean difference: $\quad 4.9 \mathrm{~m}$

RMSE: $\quad 3.9 \mathrm{~m}$ 